\title{
A Survey on 'Hikikomori' in a Provincial City in Japan and Factors of the Recovery
}

\author{
Yoshiya Kawanori \& Masahiko Kambara \\ 152-52 Sugo Takizawa Iwate \\ Japan
}

\begin{abstract}
In Japan it is one of the major issues that young adults with social withdrawal called Hikikomori would neither relate others personally nor work and spend almost whole time at home after their graduation. The purpose of this study is to research current situations of Hikikomori in a provincial capital Morioka and investigate factors of their recovery. The result showed that hikikomori is expanded from teens to fifties and it is expected that the period of hikikomori might be longer in elders. Also family members were reluctant to consult specified agencies or psychiatrists. As the result showed the important role of the psychiatric support for their recovery, it is needed the recommendation of consulting with support institutions.
\end{abstract}

Keywords: Social withdrawal, recovery factors, school refusal, avoidance of consultation

\section{Introduction}

Hikikomori is a common problem in Japan and is regarded as a characteristic to youth. It is defined as persons who avoid social situations (e.g. attending school, working, having social interactions outside of the home etc.) as a result of various factors for at least six months and become recluses in their own homes.

Though hikikomori is a phenomenon and is not a psychiatric disease, Kondo et al.[1] suggested that the great part of cases who can be interviewed were able to be diagnosed as psychiatric diseases by DMS IV. Saito [2] argued that psychiatric symptoms were generated as reactions to situations as hikikomori and it is suggested the possibilities of the onset of psychiatric diseases in the process of hikikomori.

Although the beginnings of hikikomori are common situations such as living with family as a result of the failure of getting jobs at the graduation or quit jobs, Kawanori [3] reported that 59\% of hikikomori were withdrawn over five years. In Japanese social and cultural situations the long duration of hikikomori is a big obstruction to rehabilitation in society and it is needed to support rehabilitation of hikikomori by specialized agencies. On the other hand Japanese are reluctant to consult specialized agencies. Kondo [4] reported that only $16.2 \%$ of hikikomori cases were consulted within one year at first and in $13.0 \%$ of cases first consultations were passed more than ten years. Then it is important to investigate the strategies to encourage the earlier consultation. But it is very difficult to grasp the situations of young people in social withdrawal who have not belonged to social organization such as school. Moreover the estimate of the number of hikikomori is not easy as the person with social withdrawal tends not to consult by himself. Kawakami[5] reported that the lifetime prevalence of hikikomori was $1.2 \%$ and the $0.5 \%$ of house hold had hikikomori at his survey. Then it is expected that the number of hikikomori is not small. Recently provincial governments have the interest in hikikomori and some researches reported that the rate of hikikomori was $0.15 \%$ in Shimane[6] prefecture and was $0.14 \%$ in Yamagata7] prefecture.This research aims to estimate the number of hikikomori in a provincial city and to investigate the factors of recovery from hikikomori.

\section{Method}

\section{Research I}

Nineteen welfare commissioners in the two districts in a provincial city Morioka were asked to reply a questionnaire on hikikomori at the end of a monthly meeting. The definition of hikikomori in this survey is as follows...

1.A person who neither attends school nor works and avoids interactions with others except family members and becomes recluses in their own home for at least six months. 
2.A person who neither attends school nor works and avoids interactions with others except family members and s ometimes go out for shopping.

3.Except a person who does not go out because of severe physical disabilities or diseases.

Gender and age of hikikomori and coping with hikikomori by family members were asked in the questionnaire.

\section{Research II}

Subjects who had hikikomori episode were introduced by eighteen institutions on supportive activities for Hikikomori and were interviewed on the situations in the early stage of hikikomori, in the middle stage of hikikomori and the recovery stage to explore effective supports.

Ethical matters

This study protocol was approved by the ethics committee of Iwate Prefectural University.

\section{Results}

Welfare commissioners reported that nineteen adults were considered to be in the state of Hikikomori. Prevalence calculated from this result is 0.35 percent. Prevalence by this study is higher than Shimane and Yamagata and lower than the estimate by Kondo. It is estimated by the result of this study that the number of Hikikomori in Morioka city is 466 .

Fig.1 showed age distribution of hikikomori and Fig.2 showed coping styles by family members.

Although hikikomori is regarded as a characteristic to youth, a ratio occupied by thirty's and fifty's is over $50 \%$ in this study. A large number offamilies had no action to a hikikomori member and it is suggested that family members do not feel that hikikomori is a serious problem.

Some examples of responses of welfare commissioners to an open end question on support of hikikomori were as follows;

"As persons concerned do not intend to be supported, plans to help them are not clear."

"It is difficult to communicate them as they are neighbors to welfare commissioners themselves."

"Parents are aged and do not know how to support hikikomori persons."

As a whole results suggested that welfare commissioners have difficulties to consult with persons concerned and family members as they had not concrete strategies to support hikikomori.

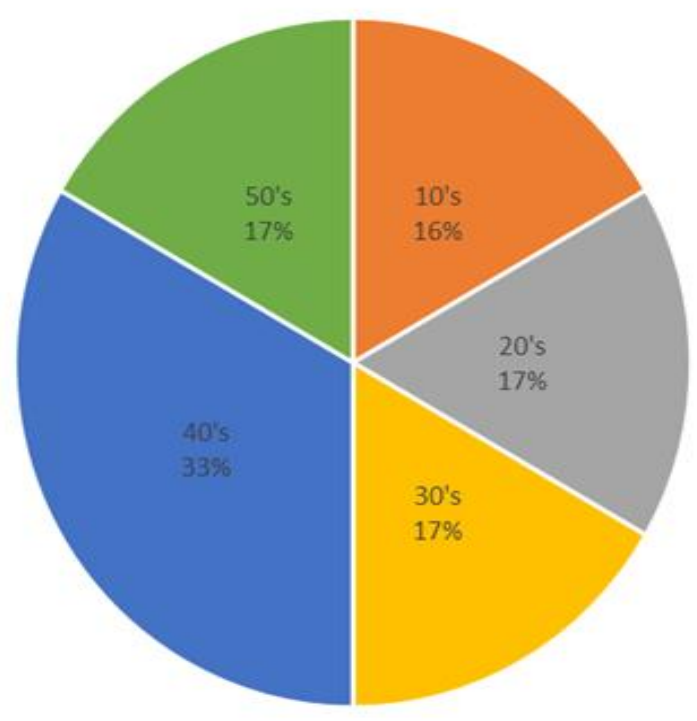

Fig.1 


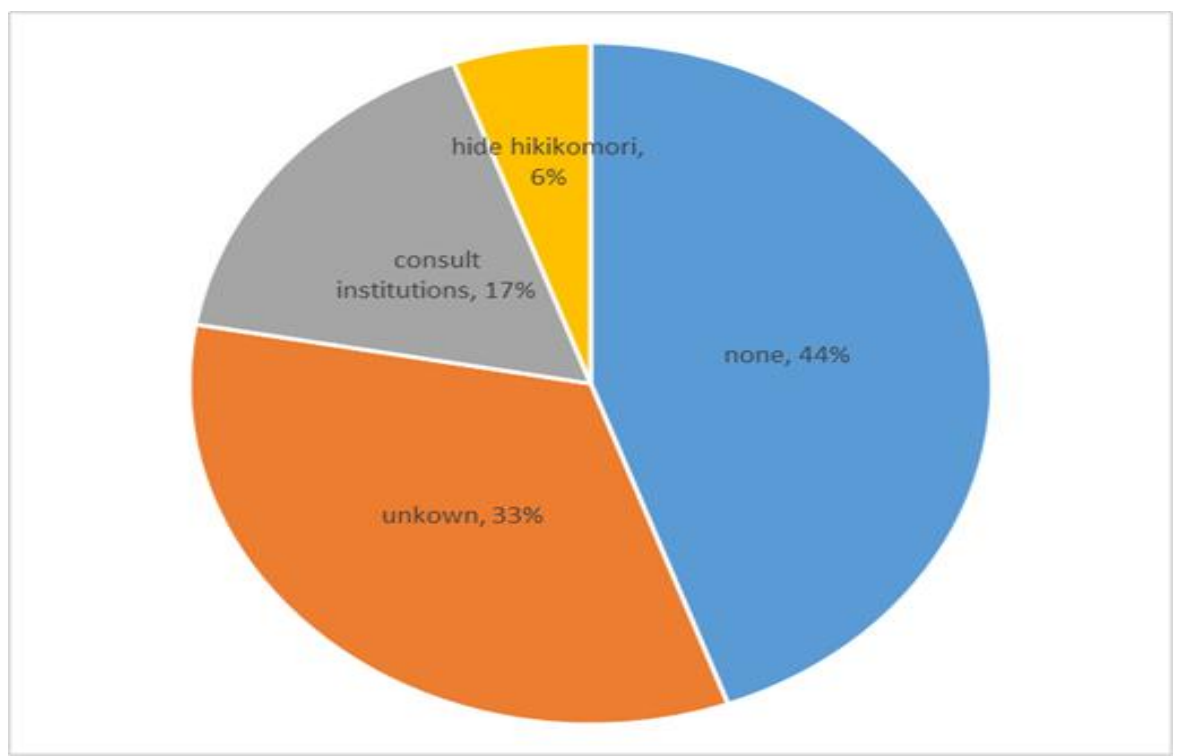

Fig.2

Results of interviews with eight subjects (male 6, female 2) who had hikikomori episode were showed in Table 1. In the process of support programs four subjects in eight were diagnosed as developmental disorders by psychiatrists. At the same time six subjects had an episode of school refusal.

\section{Table 1}

Details of case one that recovered from typical hikikomori is described in the following.

Till graduation from high school

\begin{tabular}{|c|c|c|c|c|c|}
\hline & $\begin{array}{l}\text { Age of } \\
\text { the } \\
\text { onset }\end{array}$ & $\begin{array}{l}\text { Age of } \\
\text { the } \\
\text { recovery }\end{array}$ & Diagnosis & $\begin{array}{l}\text { Trigger of } \\
\text { the onset }\end{array}$ & $\begin{array}{l}\text { Trigger of the } \\
\text { recovery }\end{array}$ \\
\hline case 1 & 17 & 29 & $\begin{array}{l}\text { Pervasive } \\
\text { developmental } \\
\text { disorders }\end{array}$ & $\begin{array}{l}\text { Hardness to } \\
\text { fit in school }\end{array}$ & $\begin{array}{l}\text { Friends who } \\
\text { had similar } \\
\text { troubles }\end{array}$ \\
\hline case 2 & 19 & 26 & $\begin{array}{l}\text { Autism } \\
\text { spectrum }\end{array}$ & $\begin{array}{l}\text { Bad } \\
\text { compromise } \\
\text { with } \\
\text { teachers }\end{array}$ & $\begin{array}{l}\text { Undertandig of } \\
\text { his own } \\
\text { disorders }\end{array}$ \\
\hline case 3 & 24 & 28 & $\begin{array}{l}\text { Anxiety } \\
\text { disorders }\end{array}$ & $\begin{array}{l}\text { Failure of } \\
\text { employment }\end{array}$ & $\begin{array}{l}\text { Reliable } \\
\text { supporters }\end{array}$ \\
\hline case 4 & 21 & 25 & $\begin{array}{l}\text { Adjustment } \\
\text { disorder }\end{array}$ & $\begin{array}{l}\text { Anxiety on } \\
\text { his future } \\
\text { career }\end{array}$ & $\begin{array}{l}\text { Counselors and } \\
\text { professors }\end{array}$ \\
\hline case 5 & 17 & 26 & $\begin{array}{l}\text { Pervasive } \\
\text { developmental } \\
\text { disorders }\end{array}$ & \begin{tabular}{|l} 
Irritable \\
bowel \\
syndrome
\end{tabular} & $\begin{array}{l}\text { Friends who } \\
\text { had similar } \\
\text { troubles }\end{array}$ \\
\hline case 6 & 19 & 29 & $\begin{array}{l}\text { Autism } \\
\text { spectrum }\end{array}$ & $\begin{array}{l}\text { Bullying in } \\
\text { school }\end{array}$ & $\begin{array}{l}\text { Undertandig of } \\
\text { his own } \\
\text { disorders }\end{array}$ \\
\hline case 7 & 33 & 36 & Depression & $\begin{array}{l}\text { Post-lingual } \\
\text { deafness }\end{array}$ & $\begin{array}{l}\text { Finding his } \\
\text { place in a } \\
\text { welfare center }\end{array}$ \\
\hline case 8 & 11 & 28 & Not visit & Unkown & $\begin{array}{l}\text { Change of } \\
\text { home } \\
\text { environment }\end{array}$ \\
\hline
\end{tabular}

The subject was quiet in childhood and had few friends. He would often spend his time in watching TV at home after elementary school was over. It was difficult for him to adapt elementary school in the upper grades and he tended to be absent himself from school. In a junior high school he would stay almost all time in an infirmary. He 
entered a high school but was tended to be absent and has given up school. After he stayed at home for two years, he entered a communication high school to be qualified and has graduated at age 21 .

A period of hikikomori

He has not tried to find a work in a high school age and every day stayed at home and spent his time in watching TV and surfing the internet. He had an ambivalent affect that he would like to go out and would stay at home and has been withdrawn from social interactions for six years. He has worried about what neighbors think and has had a feeling of guilty for family members.

Consulting on the internet

In his late twenties he consulted on the internet about his situation and was advised to consult the health and welfare center. As he would like to change his situation at the end of twenties, he consulted the health and welfare center and was recommended to visit a mental health clinic. As a result of medical examinations the diagnosis was developmental disorders.

\section{Employment support by welfare service}

He has got a disability certificate and determined to consult welfare service on employment support. He observed the employment support office for the disabled and he had a feeling that he would be able to work hard as people who had similar difficulties to him had worked in the office. His image of work has changed for two years working from scolding at failure to confidence and delight.

Regularly employment

After training in general companies his fear of others and societies has decreased and his volition to work has increased. He has got a status of a part time staff in a general company by the introduction of the employment support office.

This case needed twelve years for the recovery from hikikomori and also relative long periods were necessary for other cases in table 1 to recover. These results showed the necessity of earlier intervention.

\section{Discussion}

The result showed that hikikomori is expanded from teens to fifties and it is expected that the period of hikikomori might be longer in elders. Also it is suggested that the longer period of hikikomori would make the recovery more difficult. School refusal or failure of employment was the beginnings of hikikomori and it seemed that the lack of social belonging of hikikomori persons might obstruct their social life and they would not wish the support for social participation. At the same time family members were reluctant to consult specified agencies, as they tend to feel that the existence of hikikomori is a shame to the family in the context of Japanese traditional culture.

Though this study is based on the interviews with welfare commissioners, it is difficult for them to intervene in the private troubles as they also live in the same district and are volunteers who are asked life consultation of residents by the administration. Accordingly the support of professions in the support institutions is needed and expected to use full of information provided by welfare commissioners. The result of Table 1 suggests that the incompleteness of acquaintance of social skills underlies hikikomori, The change of plays in childhood might be related to hikikomori. In the past time children played tag, hide-and-seek, baseball or soccer outdoors. On the contrary in recent year's children tend to spend more time by playing games individually even though they may come together. Recent situations in childhood may provide insufficient opportunities to develop skills for social relationship and coping skills with stressful situations. For the difficulty of coping with stressful situations in school or employment may start social withdrawal, the change of environment in childhood might be one factor of hikikomori in Japan.

Kawanori [3] reported that the rate of visits of hikikomori to psychiatrists regularly or irregularly was $22 \%$ but this study showed seven cases in eight subjects who had recovered from hikikomori had visited to psychiatrists. This result suggested that psychiatric medication might play an important role in support of hikikomori especially in an earlier stage.As six cases had episodes of school refusal, it seemed that the spread of knowledge on hikikomori for guardians in school might be effective in preventive sense. 
Saito [8] insisted that the possibility of the transition to hikikomori was high in persons who were in the state of school refusal and lost belongingness to school by graduation. It seems that the recommendation of consulting with institutions might be important on the occasion of graduation of school refusals.

\section{References}

N. Kondo,H, Iwazaki,,M. Kobayashi,,H. Miyazawa.(2007).The Psychiatric Background of Social Withdrawal in Adolescence. Psychiat. Neurol Jap No.109Vo19. 834-843.

T. Saito.(2003). Social Withdrawal. Japanese bulletin of social psychiatry.No11.Vol3,323-328.

Y. Kawanori.(2017). Consideration about the Actual Situation of the Social Withdrawal and the Needs of Their P arents.Clinical Psychiatry,No.59 Vol10,953-958.

N. Kondo.(2010). Study on actual situation grasp of the psychiatric disorder in the pubertal social withdrawal. htt p://www.ncgmkohnodai.go.jp/subject/100/h21-jidouseisin.pdf,67-86.

N. Kawakami.(2007).Study on epidemiological survey about the mental health: General searching papers, 2004-2 006 Public welfare labor science research expenses subsidy mental health scientific research business. $h$ ttp://www.khj-h.com/pdf/soukatuhoukoku19.pdf.

Shimaneprefecture(2014).Fact-findingreport about the social withdrawal. http://www.pref.shimane.lg.jp/kenpukus omu/index.data/hikikomori-jittaityousa.pdf.

Yamagata prefecture.(2013) .Questionnaire working papers about the youth with the difficulty.http://www.pref.ya magata.jp/ou/kosodatesuishin/010003/wakamonoshien/tiikikyougikai/research/honbun.pdf,2013.

Y. Kawanori,M. Kambara.(2010).The improvement of the mental and life symptoms and duration of untreated ps ychosis in schizophrenia patients at day care centers. Chiba University Department of Education study bul letin,No.59,305-309.

T. Saito. (2014).The long-term course of "non-attendance at school" and hikikomori (social withdrawal),Japanese Journal of Clinical Psychiatry No.43 Vol10,1481-1485. 